УДК 930.2:398

\title{
П.А. Куринских
}

\section{МЕТОДОЛОГИЧЕСКИЕ ПОДХОДЫ В ИССЛЕДОВАНИИ ФОЛЬКЛОРИЗМА В ЗАРУБЕЖНОЙ И ОТЕЧЕСТВЕННОЙ ИСТОРИОГРАФИИ}

\begin{abstract}
На основе анализа работ немецких, американских, словенских и российских этнологов выделены основные методологические подходы в изучении проблем фольклоризма. Термин «фольклоризм» был предложен в 1962 г. немецким этнологом Хансом Мозером для обозначения процесса видоизменения отдельных элементов фольклора с целью придания им более зрелищных форм для демонстрации публике.

Ключевые слова: историко-культурное наследие; фольклоризм; методология исследования.
\end{abstract}

Методологические принципы исследования фольклоризма, как и любого иного культурного феномена, во многом определяются историко-социальными причинами.

По мнению ряда авторов, технологические нововведения, радикальная модернизация, массовая миграция, рост средней продолжительности жизни способствовали возникновению неуверенности в уже накопленном человеческом опыте. Эти процессы повлияли на отношение к традициям, которые стали вызывать ностальгические, романтические чувства и заставили искать новые источники информирования, которые позволили бы определить нестандартные коммуникативные пути с прошлым. Фольклоризм - социальный и культурный феномен, который представляет и возрождает народные культурные формы различными способами, ранжирующимися от научных реконструкций до народных спектаклей (performance). Отбор, распространение и продвижение отдельных аспектов традиций и культурного наследия (сфера исследований этнографов и фольклористов) особенно часто наблюдается в сфере туризма [1. С. 51].

Целью данной статьи является выявление доминирующих методологических подходов в исследовании феномена фольклоризма в зарубежной и отечественной историографии.

В работе использован ряд разработок на основе переводов, сделанных автором статьи немецких, словенских, американских и российских этнографов, содержащих историографические разделы, позволяющие проследить как историю, так и предлагаемые принципы исследования этого феномена. В силу ограниченности круга работ по проблематике, выбор историографических источников не носил случайного характера. Он осуществлялся на основе анализа теоретического и научно-прикладного вклада исследователей в изучение фольклоризма.

Впервые термин фольклоризм был предложен немецким этнологом, представителем мюнхенской школы Хансом Мозером в 1962 г. В своих работах он только поставил проблему фольклоризма как передачу и демонстрацию культуры из вторых рук [2. C. 179-180], не обозначив возможные подходы и методы его изучения.

Однако в дальнейшем тема стала разрабатываться в исследованиях немецких, словенских этнографов и фольклористов. Так, в статье «Фольклоризм в Европе. Опрос» немецкий ученый, основатель тюбингенской школы культурной антропологии Херман Баузингер [3. С. 1-8] дал общий методологический подход для рассмотрения фольклоризма как объекта исследования этнографии. Так, согласно Х. Баузингеру, основными методами изучения фольклоризма являются: анализ данных, в том числе контент-анализ СМИ, метод наблюдения, интервью, экспертный опрос, сравнительный анализ.

Рассматривая методологические подходы к изучению фольклоризма, Х. Баузингер приходит к выводу, что этнограф в первую очередь должен обращать внимание на распространенные формы проявления фольклоризма: сохранение национальных костюмов, формы сохранения обычаев, проявление первоначального фольклора в области искусства, музыки, литературы и имитация изделий народного творчества. Особое значение исследователь придавал коммерциализированным формам сохранения обычаев: фестивалям, встречам хоров (ансамблей), внесению этнической составляющей в рекламу магазинов.

Баузингер, вслед за Мозером, подчеркивал, что демонстрация фольклора как шоу, продажа фольклорных изделий, характерных для данной местности, в целях привлечения туристов являются наиболее показательными проявлениями фольклоризма. В связи с этим в развитии фольклоризма значительная роль отводится средствам массовой информации. Еще одним объектом изучения являются носители фольклоризма. К ним относятся:

- общины, объединения, организации;

- группы инициативных лиц;

- государственное сопровождение подобных проектов;

- партийно-политические фонды.

$\mathrm{X}$. Баузингер отмечал, что некоторые регионы более «восприимчивы» к фольклоризму. Например, таким регионом в Германии является Бавария [3. С. 8].

Значительное место в проявлениях фольклоризма занимают научные институты (особенно этнографические). Направлениями работы научных институтов могут быть мониторинг ремесленных и фольклорных центров, их классификация, которая должна выявить виды фольклоризма (по основным областям проявлений), меру их внедрения в процессы развития подлинного фольклора, особенности взаимовлияния двух областей.

Последующие шаги в разработке методологических подходов в изучении фольклоризма можно проследить в работах американских и словенских этнографов. Так, американский исследователь Майкл Дилан Фостер в работе «Метаморфоза каппы. Трансформация фольклора в фольклоризм в Японии» на примере традиционного 
для японского фольклора мифологического существа каппа (водяного) проанализировал механизм перехода фольклора в фольклоризм. Следует особо подчеркнуть, что в своих исследованиях М.Д. Фостер настаивал на том, что фольклор и фольклоризм - это две автономные (самостоятельные) концепции, но наиболее важным является понимание того, что данные понятия представляют собой континуум [4. С. 12].

При исследовании каппы автор подчеркивает, что механизм превращения фольклорного персонажа в явление фольклоризма невозможен без понимания, кем он являлся в японском фольклоре. М.Д. Фостер провел глубокий анализ фольклорных материалов о персонаже, включая искусствоведческие (рисунки, гравюры) и лингвистические данные. Также он рассмотрел классификацию, фиксируя на карте варианты имен и происхождений слова «каппа». В результате он пришел к выводу, что основной причиной превращения каппы из «единицы» фольклора в «единицу» фольклоризма является индустриализация и урбанизация. М.Д. Фостер отметил три этапа этой метаморфозы:

1) придание фольклорному персонажу каппы черт, присущих человеку. В фольклоре «каппа» - водное божество, призванное помочь объяснить мистический мир человеческой реальности извне. «Каппа» фольклоризма же создан объяснить и более четко визуализировать человеческую реальность;

2) изначальное значение мифологического существа «исчезало» из памяти благодаря работе карикатуристов и мультипликаторов. В результате сексуально угрожающее, физически омерзительное существо мужского пола в фольклоре на данном этапе превратилось в дружелюбное, физически привлекательное и соблазнительное существо женского пола в фольклоризме. Новые функции каппы стали естественными для подрастающего поколения;

3) использование уже трансформированного художественного образа как рекламы идеального места отдыха горожан в сельской местности, использующей ключевые слова «домашний», «ностальгия по культурным ландшафтам».

По сути, «каппа» фольклоризма - это изобретение, выдумка, одомашненная версия, видоизмененная в течение определенного времени с помощью литературного и художественного маркетинга. Однако именно фольклоризм позволил «сохранить» данный персонаж вне музейных фольклорных экспозиций.

М.Д. Фостер полагает, что образ «каппы», вне зависимости от того, относим мы его к фольклору или фольклоризму, никогда не был статичен, он «отвечал» динамичной заинтересованности людей в данном образе. То есть наиболее важные функции его образа были «переизобретены» в разных контекстах. Как водное божество, считал исследователь, каппа поддерживал экономическую выживаемость общины, так как ранее функцией каппы была ирригация и обогащение почвы. В настоящее же время экономическая стабильность общины поддерживается благодаря туризму [4. С. 18-19].

Исходя из анализа работы М.Д. Фостера, можно выделить ряд методов, применяемых исследователем при изучении вопросов фольклоризма на примере «каппы». Историко-генетический метод и анализ документов позволил автору восстановить изначальный облик каппы, начиная со Средневековья. Метод исторической периодизации сделал возможным определить основные этапы видоизменения единицы фольклора и фольклоризма. С помощью структурно-функционального и системного анализа были выявлены изменения функций фольклора и фольклоризма. В статье отражена и возможность использования метода картографирования при изучении данной проблематики.

В работах ряда словенских этнографов прослеживается формирование концепта «фольклоризм» начиная с 1930-х гг. Так, значительный интерес словенской исследовательницы С.П. Истенич вызывали разработки концепта аутентичности в областях экологического, этнического, альтернативного и этнокультурного туризма. При исследовании популярнейшего фольклорного фестиваля в Любляне «Сельская свадьба» С.П. Истенич использовала метод анализа данных, в том числе опубликованных в средствах массовой информации. Ею отмечены отличительные черты фольклоризма. Это принадлежность к различным социальным слоям и искажение в той или иной степени черт народного костюма, песни, танца. Анализ же работ других словенских исследователей по проблемам фолькоризма позволяет проследить общую направленность словенской школы в изучении фольклоризма как феномена, берущего свое начало в сельской местности и связанного с историко-культурным наследием [1].

Исследуя отечественную историографию, можно, во-первых, констатировать, что в советской и российской историографии исследования по поднимаемой проблематике единичны. Во-вторых, фольклоризм рассматривается как явление культуры, характерное только для литературы и музыки. В этой связи следует отметить работы В.Е. Гусева. Отличительной чертой методологических подходов его школы в рассмотрении фольклора и фольклоризма стала трактовка феноменов с точки зрения развития культуры, изменения социальной структуры. Он определяет фольклоризм как процесс, который адаптирует фольклор $\kappa$ новому социальному контексту [5].

Ситуация несколько изменилась в начале 2000-х гг. В этой связи следует отметить работы И.А. Колобковой, в том числе кандидатскую диссертацию «Проблема фольклоризма в современном народном декоративном искусстве (на материалах современной глиняной игрушки)» (2011). Избрав глиняную игрушку как вид современного народного декоративного искусства в качестве объекта исследования, И.В. Колобкова выделила подлинные исторические очаги традиционной глиняной игрушки, сведения о которых зафиксированы в экспедиционных данных о гончарных центрах. На основе экспедиционных, архивных и музейно-коллекционных данных автором были изучены четыре традиционных центра глиняной игрушки. Новообразованные центры были определены путем изучения материалов Всероссийских смотров-конкурсов и анализа материалов, представленных в сети Интернет [6. С. 3-4]. 
И.А. Колобковой за основу были взяты три основных критерия фольклорности: коллективность, традиционность, целостность художественной системы. При их применении была выявлена художественная специфика, отличающая анализируемые центры от внешне схожих, но не обладающих системной и содержательной глубиной явлений фольклоризма [Там же. С. 23]. В целом подходы И.В. Колобковой не противоречат методике, предложенной Х. Баузингером в 1969 г. Так, рассмотрев деятельность ремесленных центров, занимающихся производством глиняной игрушки, она впервые отметила восприимчивость традиционной культуры к фольклоризму, уделив немаловажную роль государственному сопровождению подобных проектов (деятельность «Государственного республиканского центра русского фольклора» и «Государственного Российского дома народного творчества» Министерства культуры РФ). В то же время диссертационная работа И.В. Колобковой, с нашей точки зрения, стала ярчайшим примером определения места научных (особенно этнографических) институтов в проявлениях фольклоризма.
Резюмируя анализ работ, можно отметить следующее:

- на основе анализа выборочных историографических источников можно сформировать рабочую гипотезу, что при исследовании феномена фольклоризма активно используются методологические подходы системного анализа (комплексность, выявление механизма трансформации системообразующих связей социальных институтов под воздействием «среды») и традиционный методический инструментарий исторических наук (полевые исследования, анализ первичных и вторичных источников, разные формы сравнительно-исторического анализа социальных процессов и явлений и т.д.);

- в исследованиях активно используются социологические и этнографические качественные и количественные методы (наблюдение, интервью, экспертный опрос, контент-анализ, анкетный опрос и др.);

- принципиальных отличий в методологических подходах и в научном инструментарии как в отечественной, так и в зарубежной историографии не прослеживается.

\section{ЛИТЕРАТУРА}

1. Istenič S.P. Texts and contexts of folklorism // Traditiones, Journal of the Institute of Slovenian Ethnology and Institute of Ethnomusicology SRC SASA. 2011. № 40. P. 3 .

2. Moser H. Vom Folklorismus in unserer Zeit // Zeitschrift für Volkskunde. 1962. № 58.

3. Bausinger H. «Folklorismus» in Europa. Eine Umfrage // Zeitschrift fur Volkskunde. 1969. № 65.

4. Foster M.D. The Metamorphosis of the Kappa: Transformation of Folklore to Folklorism in Japan // Asian Folklore Studies. 1998. № 57. P. 1.

5. Гусев В.Е. Фольклор как универсальный тип субкультуры // В диапазоне гуманитарного знания. Серия «Мыслители». 2001. Вып. 4.

6. Колобкова И.В. Проблема фольклоризма в современном народном декоративном искусстве (на материалах современной глиняной игрушки) : автореф. дис. ... канд. искусствоведения. СПб., 2011.27 с.

Статья представлена научной редакцией «История» 28 мая 2015 г.

\section{METHODOLOGICAL APPROACHES IN RUSSIAN AND FOREIGN FOLKLORISM RESEARCH}

Tomsk State University Journal, 2016, 403, 79-81. DOI: 10.17223/15617793/403/13

Kurinskikh Polina A. Peter the Great Museum of Anthropology and Ethnography (the Kunstkamera), Russian Academy of Sciences (Saint Petersburg, Russian Federation). E-mail: p.sadovaja@gmail.com

Keywords: folklorism; methodology; cultural heritage.

The research is relevant due to ethnic elements popularization in social, political (use of electorate's local ethnic culture in political party's work) and economic (tourism) life spheres. The aim of this article is to show the main methodological approaches in foreign and Russian folklorism research. The term folklorism was suggested in 1962 by German ethnologist Hans Moser. He wrote that the folklorism is "second-hand mediation and presentation of folk culture". Moser meant most popular folklore elements transformation for shows and performances. But he did not suggest any methodological approach for the new concept. Several years later, another German scientist Herman Bausinger suggested his methodological approach in which he especially noted the role of media, scientific organisations, the most popular form of folklorism (e.g., use of indigenous dress), regional folklorism (e.g., Bavaria in Germany). More methodological approaches to folklorism are described in American, Slovenian and Russian ethnological research works. In his research on the kappa belief and its transformation from folklore to folklorism, American folklore researcher Michael Dylan Foster used a historical-genetic method, document analysis, mapping, a historical periodization method, structure functional and system analysis. Irina A. Kolobkova was interested in clay toys as a modern folk decorative art. She used observation, interview, photo fixation, comparative analysis. The following conclusions and summary can be made from the above: 1 . According to historiography, the author has formed an operational hypothesis: folklorism research uses system analysis methodological approaches. It means integrity, transformation of social institution system constitutive relation under the environmental influence. Traditional historical methods (comparative analysis, document analysis, field work and other) are also used; 2. Folklorism study uses quantity and quality sociological and ethnological methods (overview, interview, public opinion polls, content analysis); 3 . There are no principal differences in foreign and Russian folklorism methodological approaches.

\section{REFERENCES}

1. Istenič, S.P. (2011) Texts and contexts of folklorism. Traditiones, Journal of the Institute of Slovenian Ethnology and Institute of Ethnomusicology SRC SASA. 40. pp. 51-74.

2. Moser, N. (1962) Vom Folklorismus in unserer Zeit [On folklorism in our time]. Zeitschrift für Volkskunde. 58.

3. Bausinger, H. (1969) "Folklorismus" in Europa. Eine Umfrage ["Folklorism" in Europe. A survey]. Zeitschrift fur Volkskunde. 65.

4. Foster, M.D. (1998) The Metamorphosis of the Kappa: Transformation of Folklore to Folklorism in Japan. Asian Folklore Studies. 57.

5. Gusev, V.E. (2001) Fol'klor kak universal'nyy tip subkul'tury [Folklore as a universal type of subculture]. V diapazone gumanitarnogo znaniya. Seriya "Mysliteli". 4

6. Kolobkova, I.V. (2011) Problema fol'klorizma v sovremennom narodnom dekorativnom iskusstve (na materialakh sovremennoy glinyanoy igrushki) [Folklorism problem in contemporary folk decorative art (on materials of modern clay toys)]. Abstract of Art History Cand. Diss. St. Petersburg. 